\title{
Body mass index and body image anxiety in a sample of undergraduate students
}

\author{
Pop Cristiana Lucretia ${ }^{\mathrm{ABCDE}}$ \\ Physical Education and Sport Department, Bucharest University of Economic Studies, Romania
}

Authors' Contribution: A - Study design; B - Data collection; C - Statistical analysis; D - Manuscript Preparation; E - Funds Collection.

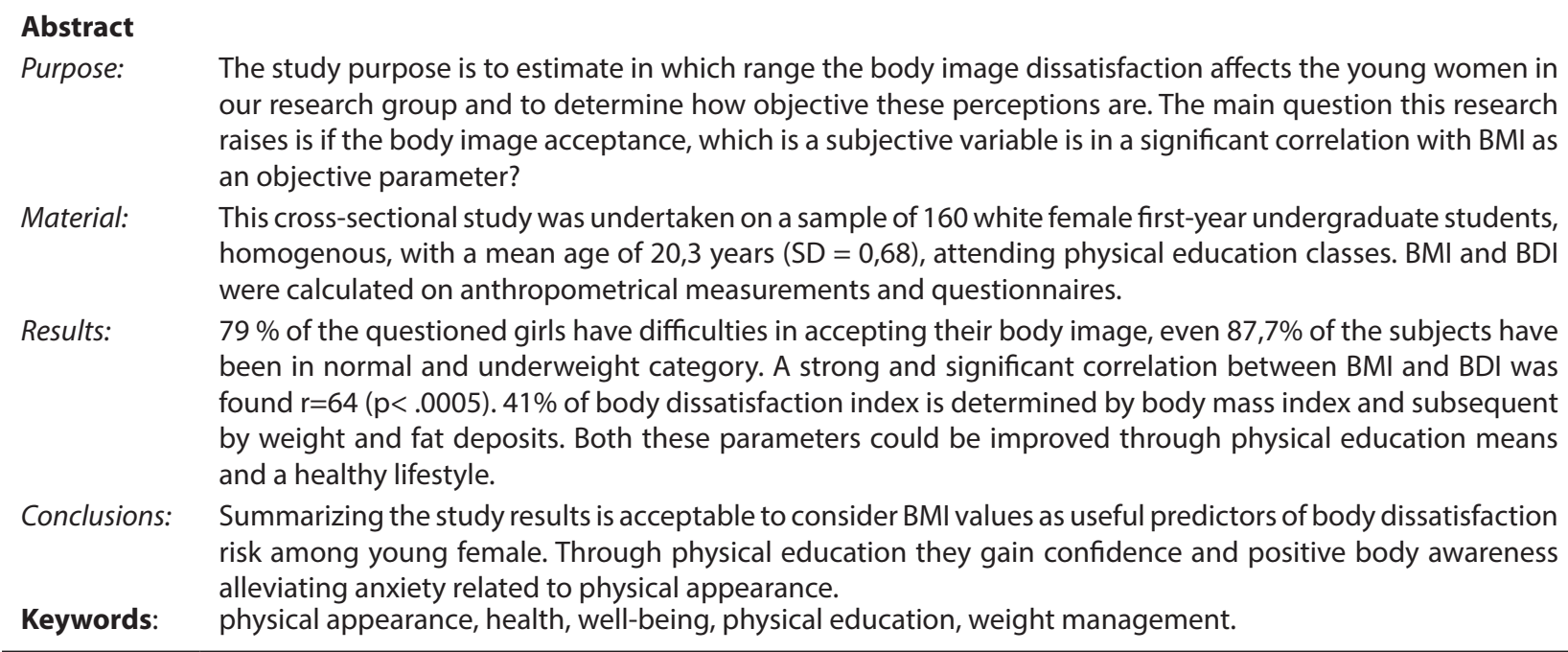

\section{Introduction}

The physical appearance is one of the first individual characteristics noticed by others and has an important impact in social interactions. Appearance in general and body image in particular have become very important constructs in contemporary Western societies [1]. Body image is not just a cognitive construct, but also a reflection of attitudes in interaction with others. The tendency to link physical attractiveness with positive personal qualities became a cultural stereotype not only in western culture, but globally also. The avalanche of perfect bodies in mass media, advertising and social media is an overburden for our subconscious, determining us to accept that "what is beautiful is good and desirable"; physical attractiveness being often linked with success.

In present times the personal physical image is a form of gaining a distinct place in the social environment and for achieving this status the investments in body appearance (cosmetics products and procedures, piercing and tattoos, plastic surgeries, sport materials and equipment, etc) are notably for both: women and men.

As they grow up children are building a picture or image of themselves. This image develops through the things that they can or cannot do and by how other people see them. Poor opinion of our body can cause low self esteem and self confidence, eating disorders and even depression. A recent study has concluded that $61.6 \%$ of adolescents with BID endorsed depressive symptoms [2]. An important contribution in constructing the youth's body image has the media. Constantly watching 'perfect' bodies can feed their insecurities over attractiveness (c) Pop Cristiana Lucretia, 2018 doi:10.15561/20755279.2018.0204 and weight. Studies show that idealized body image contributes to eating disorders as anorexia nervosa or bulimia, steroid use, protein supplements [3] and eventually plastic surgery.

During adolescence girls, more than boys, have particular concerns about weight, body shape and self image. There are scientific evidence that body image is experienced negatively by the majority of women and girls $[4,5]$. Many are dissatisfied with their body size and weight because slimness is seen as the desirable standard and as the beauty pattern especially for young women. In adulthood also the underweight is much more prevalent among women compared with men [6].

Physical activity is of fundamental importance for maintaining the life functions and it is an essential part of having a healthy lifestyle. It has been proven that a certain level of physical activities has a protective role in the prophylaxis and development of cardiovascular disease, metabolic and skeletal disorders, and even mental illness [7]. Leisure and physical activity has been shown to be an effective intervention for improving body image and having beneficial emotional effects across all ages and both genders. In an extensive meta-analysis of 35 studies Reel and colleagues [8] examined the association between exercise and body concerns and the outcome was a medium overall size effect ( $E S=0,45-0,47)$. The authors concluded that exercise has a significant, positive effect on body image, body esteem and physical self concept. This statement is encouraging for PE teachers to design and deliver programs with this specific goal in mind: improving student's body image for their physical and emotional well-being. 
This study purpose is to estimate in which range the body image dissatisfaction affects the young women in our research group and to determine how objective these perceptions are. The main question this paper raises is if the body image acceptance, which is a subjective variable is in a significant correlation with BMI as an objective parameter? Therefore I estimate the average BMI for 19-24 years old female student population and the share of different weight sub-groups in the study sample. In the discussion section a case was made out for exercise intervention on changing body image and overcoming young females anxiety related with physical appearance.

\section{Materials and methods}

This cross-sectional study was undertaken on a sample of 160 white female university students. The age of the participants ranged from 19 to 24 years; the mean age was 20,3 years $(\mathrm{SD}=0,68)$ and the low coefficient of variance $(\mathrm{CV}=3,45 \%)$ demonstrate a high sample homogeneity.

The participants were randomly selected from those attending physical education classes in tertiary economic education. Therefore we assumed to have a healthy, cooperative, young women research sample with an urban lifestyle. The students' inclusion in the research sample was voluntary agreed.

The measurements and questionnaire were applied in a context related with physical activities, health, fitness and body shape improvement.

The anthropometrical measurements - high and weight - enable us to calculate the Body Mass Index (BMI) as an objective reference data. We consider the participants on this study as young adults as time the height values for the sample we measured are definitive. The female growth speed trails off to zero at about 15 or 16 years. We preferred direct measurement against selfreported height and weight. The subjects were measured and weigh in light sport equipment, barefooteed, using measurement bar and electronic weight scale. The majority of participants $(66 \%)$ were within the normal BMI interval: between 18,5 and $24,9 \mathrm{~g} / \mathrm{cm}^{2}$, with a mean value of $20,94 \mathrm{~kg} / \mathrm{m}^{2}(\mathrm{SD}=3,3)$.

The subjects completed anonymously a questionnaire aimed to assess their range of body size satisfaction / dissatisfaction. For assessing body dissatisfaction we used the Contour Drawing Rating Scale [9]. The CDRS consists of nine drawings of a female figure, each drawing increasing in size from extremely thin (1) to very obese (9). The young women were asked to rate their ideal figure (how they ideally expected to look like) and their current size (perceived figure). The discrepancy between the ideal and current size scores (current - ideal $>0$ ) represents the index of body size dissatisfaction (BDI).
Using descriptive statistics for each variable we analysed summaries about the sample and about the collected data. For the pared variables we calculated the Pearson correlation coefficient (r) and further we tested its statistical significance using the " $t$ " test. Then we compared the " $\mathrm{t}$ " score figured for the actual correlation in the study, using the standard t table cutoffs ( $\mathrm{df}=\mathrm{N}-2)$.

Using the correlation coefficient values we calculated the coefficient of determination: $\mathrm{r}^{2}$ - in order to determine the proportion of variance explained by one of the variables. We used graphical method to represent the gap between objective BMI data and subjective body image reported by respondents.

\section{Results}

BMI is a measure of body fat based on height and weight, and the normal range is usually considered as 18.5 to $24.99 \mathrm{~kg} / \mathrm{cm}^{2}$, with anything over 25 considered overweight and over 30, obese. Values less than $18.5 \mathrm{~kg} /$ $\mathrm{cm}^{2}$ are related with thin bodies or being underweight. In our research sample, the distribution of BMI (see Table 1) shows a prevalence of normal and low values $(88.75 \%)$.

The BMI mean value $-20,93 \mathrm{~kg} / \mathrm{cm}^{2}(\mathrm{SD}=3,30)$ is equivalent with a slander figure, corresponding to an average high of $1,65 \mathrm{~m}(\mathrm{SD}=0,06)$ and an average weight of $\sim 57 \mathrm{~kg}(56,99 \mathrm{~kg}$; $\mathrm{SD}=9,70)$.

However $79 \%$ of the questioned girls have difficulties in accepting their body image, and the first reason they gave is weight (13\% want to gain weight and $66 \%$ want to lose weight). Just $21 \%$ of subjects positively evaluate the shape and size of their body. The next table (Table 2) illustrates the distribution of body dissatisfaction answers relative to BMI:

More interesting is that $46 \%$ from subjects in the underweight group are not satisfied with their body size, willing to lose more weight. From the normal weight group just 13,125\% young women are pleased with their physical appearance. The mean value of body dissatisfaction index in our sample is BDI = -1,2 considering that in average each young women reported an ideal thinner shape and a slander figure comparing with the actual perceived silhouette.

Testing the study hypothesis we find that body dissatisfaction $(\mathrm{M}=-1,2 ; \mathrm{SD}=1,4)$ is strongly correlated with BMI: $r(158)=.64, p<.0005$. Because $r \neq 0$ the null hypothesis was rejected and the alternative hypothesis might be accepted.

Computing also the statistical significance of this result we obtained a " $\mathrm{t}$ " value higher than " $\mathrm{t}$ critic": $\mathrm{t}(158)=$ $8,49<3,35 ; \mathrm{p}<.0005$. The coefficient of determination $\mathrm{r}^{2}=$ 0,41 , implies that $41 \%$ of variance in body dissatisfaction is explained by body mass index and physical appearance.

Table 1. BMI distribution

\begin{tabular}{lllll}
\hline BMI & Underweight & Normal weight & Overweight & Obese \\
\hline Units & 37 & 105 & 15 & 3 \\
$\%$ & $23,125 \%$ & $65,625 \%$ & $9,375 \%$ & $1,875 \%$ \\
\hline
\end{tabular}


Table 2. Body size satisfaction / dissatisfaction

\begin{tabular}{|c|c|c|c|c|}
\hline & $\begin{array}{l}\text { Body size } \\
\text { perception/ideal }\end{array}$ & $\begin{array}{l}\text { Too thin } \\
\text { Index }<0\end{array}$ & Perceived = ideal & $\begin{array}{l}\text { Too heavy } \\
\text { Index }>0\end{array}$ \\
\hline & Units & 21 & 34 & 105 \\
\hline & $\%$ & $13 \%$ & $21 \%$ & $66 \%$ \\
\hline \multirow{3}{*}{$\begin{array}{l}\text { B } \\
\text { M } \\
\text { I }\end{array}$} & Underweight & 8 & 12 & 17 \\
\hline & Normal weight & 13 & 21 & 71 \\
\hline & Overweight \& obese & - & 1 & $15+3$ \\
\hline
\end{tabular}

This results support physical activity, which has certain results in improving body shape and its functional efficiency.

\section{Discussion}

Comparing the BMI results with other studies on female samples in Europe we find similarities and differences. An extensive study on females aged between 18 and 34 years [6], in Sweden $(\mathrm{n}=1967)$ returns a different distribution (see Table 3):

The prevalence of underweight decreases naturally with age, as time the percentage is growing in the overweight and obese section. There are similarities regarding the normal weight percentage.

In a recent study on a sample of 884 teenagers $(\mathrm{M}=$ 14, 29 years old, SD = 1,29), from Spain the average BMI for girls was 21,98, with average values of 1,59 $\mathrm{m}$ high and $56,09 \mathrm{~kg}$ weight [10]. Considering the age difference (from 14,29 to 20,3), and the lower BMI value, we consider the prevalence of normal weight and underweight in our sample as being confirmed.

We kept the BMI comparison in European geographical space and Caucasian racial typology because a study on female students of same age $(M=19,99, S D=4,79)$ in USA returns significantly bigger values $-\mathrm{M}=24,52 \mathrm{~kg} /$ $\mathrm{m}^{2}(\mathrm{SD}=5,69)$, with approximately $30 \%$ of the sample maintaining a BMI of 25 or greater, indicating that they were overweight or obese [11].

Negative body image has usually been defined as dissatisfaction with one's physical appearance. Body image dissatisfaction is a reality for a large share in our research sample. $79 \%$ of the young women questioned, wanted to change something on their body shape and size and eventually to lose weight. Even $87,7 \%$ of the subjects have been in normal and underweight category, most of them, $66 \%$ wanted to lose weight, for an ideal, slimmer silhouette. This data confirm the thesis that landmarks that society promotes are very severe for most girls and young women and put them in a position of inferiority, repercussions on self esteem and self confidence [12].

The following graph (see Fig. 1) reflects de difference between BMI values and the weight perception and how young women tend to distort their physical dimensions. In this research sample $66 \%$ of the girls had normal weight and $66 \%$ of them wanted to lose weight; while the BMI results had a normal distribution, the body dissatisfaction index (BDI) had an ascendant trend. This difference between the two trend lines represents the body image disturbed perception. In percentage it can be quantified in around $55 \%$ of subjects with normal weight, but perceiving their self body mostly too heavy.

Disturbed self perception is usually associated with preoccupation, insecure attitude or seeking reassurance in peer's opinion. An explanation for this insecurity is the fashion industry's controversial promotion of underweight models and unrealistic imagery, which in time created the Western cultural pattern. The question which arises is how could this postmodern society to overcome the twenty-first century frustration, depressions, anxieties and psychoses when natural beauty has been annulated by botox's dictatorship [4], the cult of anorexia and emaciated super models?

An important part (41\%) of body dissatisfaction is determined by body mass index and subsequent by weight and fat deposits. It means that body image can be enhanced in $41 \%$ with physical education means, being in know that the most commonly mentioned PE objective are improving the state of health and a harmonious physical development. Even body image acceptance is a subjective issue, depending on cultural and social factors, yet we find a consistent, statistical significant correlation with BMI (r $(158)=0.64, p<.0005)$. The explanation could consist in body composition representing the body fat and muscle mass ration. Fat tissue contains no water and is bigger in volume comparative with muscle tissue which has higher density [13]. A higher percentage of body fat increase the

Table 3. Comparing BMI distribution

\begin{tabular}{lllll}
\hline BMI & $<\mathbf{1 8 , 5} \mathbf{~ k g} / \mathbf{m}^{2}$ & $\mathbf{1 8 , 6 - 2 4 . 9}$ & $\mathbf{2 5 - 2 9 , 9}$ & $>\mathbf{3 0 ~} \mathbf{~ k g}$ \\
\hline Sweden & $5,7 \%$ & $68,8 \%$ & $18,4 \%$ & $7 \%$ \\
Romania & $23,1 \%$ & $65,6 \%$ & $9,4 \%$ & $1,9 \%$ \\
\hline
\end{tabular}




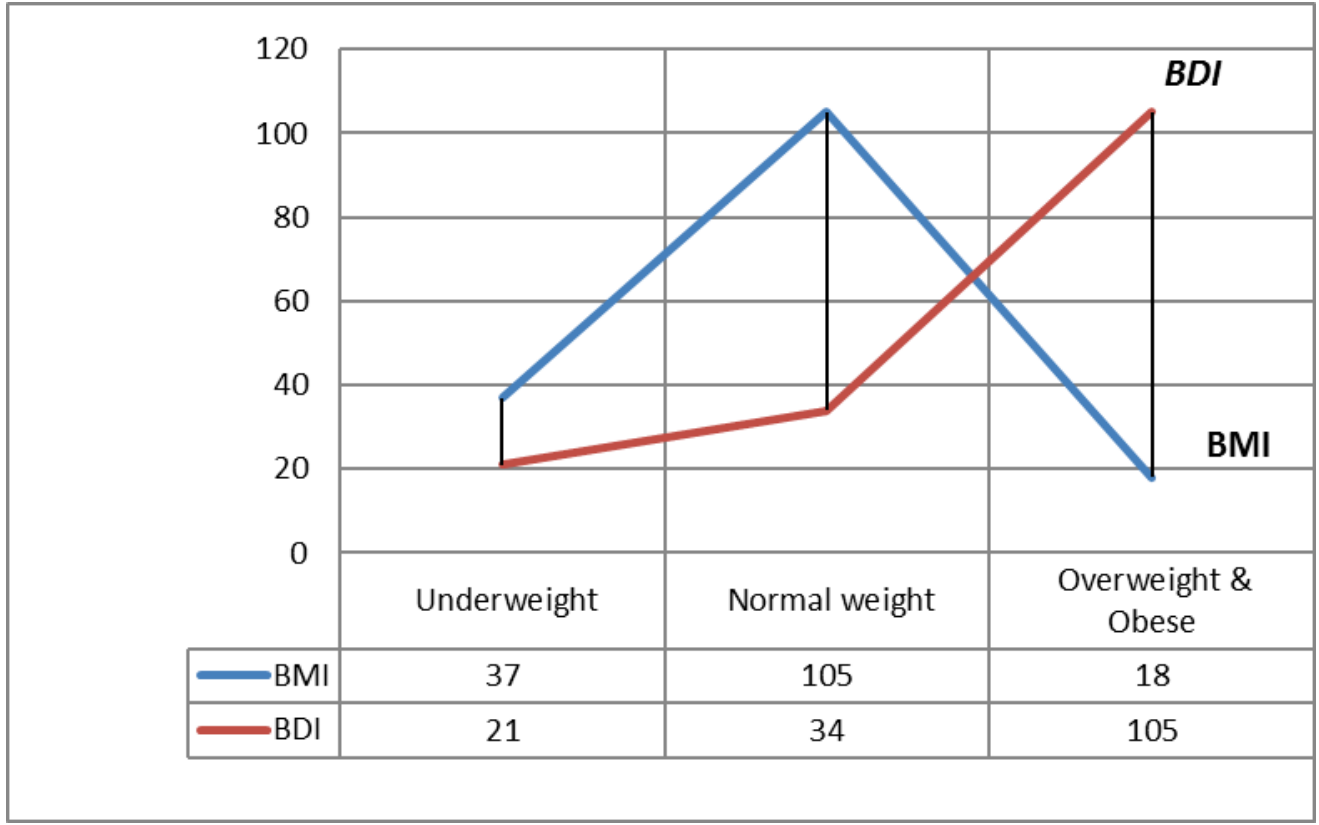

Fig. 1. Body dissatisfaction index versus BMI distribution

overall body volume regardless the BMI values.

Summarizing the obtained data is acceptable to consider that BMI values could be useful predictors of body dissatisfaction risk among young female. Our conclusion are confirmed by others studies' results investigating women samples, generally students, in divers cultural and ethnic regions. Jaworowska and Bazylak [14] have found in a sample of Polish female students almost the same percentage $(65.6 \%)$ of body dissatisfaction. In Brazil women seems to be more indulgent with their appearance, whereas the prevalence of dissatisfaction reported was 47.3\% [15]. Among a Pakistani students sample body dissatisfaction was complete: $45.6 \%$ of the respondents perceived their self body as too heavy, while $54.4 \%$ perceived it as too thin [16]. In a different cultural environment, in Saudi Arabia, among a group of young female students aged $21.02( \pm 1.48 \mathrm{SD})$ with a BMI mean value of 22.79 ( $\pm 4.71 \mathrm{SD}$ ) $26.4 \%$ reported to be satisfied, $18.6 \%$ perceived self body as too thin, while $55 \%$ perceived as being too heavy and wanted to lose weight [17]. These results are close to the percentage obtained in our study: $21 \%$ satisfied, $13 \%$ wanted to gain weight and $66 \%$ wanted to lose weight.

There are scientific studies which are linking women's body dissatisfaction and low self-esteem for physical appearance $[13,18]$. This perception can have repercussions in lowering self-esteem for physical appearance especially around 20 years of age, when young women are still studying, but right before important life choices as a careear or a life partner. A systematic review concluded that weight management and behavioral interventions could be successful by boosting self-esteem and increasing satisfaction with body areas too [19].

Practical interventions and scientific studies demonstrate without any doubt the potential positive effect for exercise to improve both physical and psychological well-being. In the psychological well-being category we can frame the perceptions, opinions and feelings related with body image, health condition, self esteem, etc, all of them improvable through physical exercise. Three different metha-analyses [20-22] draw the same consistent conclusion: exercise has significant positive effects on body image. More interesting seems to be the mechanism that could moderate the effects of exercise on body image.

Changes in objective indices of physical fitness play a minor role in body image change, whereas improvements in perceived fitness and self-efficacy appear to be important mechanisms by which exercise improves body image. There is no direct correlation between objective progress in fitness level and the subjective perception of being fit or more functionally efficient [23]. The PE teacher can inspire students with self body acceptance and self confidence by shifting the focus away from appearance and emphasizing the physical and mental benefits of exercise. This study discloses the unbreakable relationship between mind and body, meaning that every intervention at physical level will have effects on emotional and physical well-being too. This holistic approach offers us a subtle instrument for changing mentalities and attitudes in addition to physical skills and abilities [12].

The exercise intervention on changing body image depends on frequency and intensity of training [24]. The changes in body image are positively when the exercise are performed on more days per week and at least at a moderate intensity. Aerobic exercise, strength-training, and combined aerobic/strength-training interventions are equally effective. The type of exercise depends more on preferences and personal goals. A sensitive task for a teacher dealing with students with a low self image 
acceptance is to help them to set realistic and achievable goals through appropriate exercise.

The satisfaction gained from exercising can eventually become an intrinsic motivation, especially when the practitioner internalizes the idea that effort has positive effects on enhancing perceptions about body shape and self-image.

\section{Conclusions}

Regarding subjective young women's body image perception we conclude that it surpass the normal anthropometrical references regarding average body mass. Under the social and cultural patterns pressure a majority of women are not satisfied with their body shape regardless the BMI values and identify their ideal body with a thinner version. Even underweight persons are willing to lose weight in order to correspond to an expected physical attractiveness standard. The normality for female students around 20 years of age seems to be a constant preoccupation for losing weight and an ultrathin body is their beauty ideal.

$41 \%$ of body dissatisfaction index is determined by body mass index and subsequent by weight and fat deposits. Both these parameters could be improved through physical and health education. An increased number of adequate physical activities, spending time outdoors, a healthy lifestyle or cutting out unhealthy foods are a few steps to take for increasing the female student's physical tonus and could offer an alternative to this eternal and quasi-globalised body dissatisfaction.

Using just one parameter for estimating body fat is a limitation of this study. There is a credible possibility that other measurements as body composition, waist - hip ratio or height - waist ratio in relation with body dissatisfaction in young women sample to return different result.

\section{Conflict of interests}

The author declares that there is no conflict of interest.

\section{Reference}

1. Tiggemann M. Sociocultural Perspectives on Human Appearance and Body Image. In Body Image. New York: The Guilford Press; 2011. P.12-19.

2. Flores-Cornejo F, Kamego-Tome M, Zapata-Pachas MA, Alvarado GF. Association between body image dissatisfaction and depressive symptoms in adolescents. Revista Brasileira de Psiquiatria, 2017;39:316-22. doi:10.1590/1516-44462016-1947.

3. Hogan MG, Strasburger VC. Body Image, Eating Disorders, and the Media. Adolesc Med, 2008;19:521-546.

4. Delerm P. Telefonul mobil. In Garcin J (Ed.), Noile mitologii, Bucuresti: Art Pub.; 2009. P. 45.

5. Furham, A., Badmin, N., Sneade, I. (2002). Body Image Dissatisfaction: Gender Differences in Eating Attitudes, Selfesteem, and reasons for exercise. The Journal of Psyhology, $136,581-596$.

6. Ali SM, Lindstrom M. Socioeconomic, psychosocial, behavioural, and psychological determinants of BMI among young women: differing patterns for underweight and overweight /obesity. Eur J Public Health, 2006;16 (3): 324330

7. Andersen LB. Physical activity in adolescents. Jornal de Pediatria, 2009;85(4): 281-283.

8. Reel J, Greenleaf C, Baker WK, Aragon S, Bishop D, Cachaper Handwerk P, Hattie J. Relation of body concerns and exercise behavior. A meta-analysis. Psyhological Reports, 2007;101:927-942.

9. Thompson MA, Gray JJ. Development and validation of a New Body Image Assessment Scale. Journal of Personality Assessment, 1991;64:258-269.

10.Grao-Cruces A, Nuviala A, Fernández-Martínez A, Pérez-Turpin A. Association of physical self-concept with physical activity, life satisfaction and. Mediterranean diet in adolescents. Kinesiology, 2014;46(1):3-11.

11. Markey CN, Markey PM. Correlates of Young Women's Interest in Obtaining Cosmetic Surgery. Sex Roles, 2009;61:158-166.

12.Pop CL. Overweight - Cultural and Educational Aspects. Revista Românească pentru Educaţie Multidimensională, 2015;7(2):133-140.

13.Pop CL. Self - Esteem and Body Image Perception in a Sample of University Students. Eurasian Journal of Educational
Research, 2016;16: 31-44. doi:10.14689/ejer.2016.64.2

14.Jaworowska A, Bazylak B. An outbreak of body weight dissatisfaction associated with self-perceived BMI and dieting among female pharmacy students. Biomed Pharmacother, 2009;63 (9): 679-692.

15.Costa CL, de Vasconcelos A. Influence of socioeconomic, behavioral and nutritional factors on dissatisfaction with body image among female university students in Florianopolis, SC. Rev Bras Epidemiol, 2010;13 (4):665-676.

16.Khan AN, Khalid S, Khan H, Jabeen M. Impact of today's media on university student's body image in Pakistan: a conservative, developing country's perspective. BMC Public Health, 2011;11:379-382.

17.As-Sa'edi E, Sheerah S, Al-Ayoubi R, Al-Jehani A, Tajaddin W, Habeeb H. Body image dissatisfaction: Prevalence and relation to body mass index among female medical students in Taibah University. Journal of Taibah Univ. Medical Sciences, 2011;8 (2): 126-133.

18.Daniali S, Azadbakht L, Mostafavi F. Relationship between body satisfaction with self esteem and unhealthy body weight management. J Educ Health Promot. 2013;31(2):29-32.

19.Poobalan AS, Aucott LS, Precious E, Crombie IK, Smith WC. Weight loss interventions in young people (18 to 25 year olds): A systematic review. Obes Rev. 2010;11:580-92.

20.Martin Ginis KA, Eng JJ, Arbour KP, Hartman JW, Phillips SM. Mind over muscle? Sex differences in the relationship between body image change and subjective and objective physical changes following a 12-week strength-training program. Body Image: An International Journal of Research, 2005;2:363-372.

21.Sonstroem RJ. The physical self-system: A mediator of exercise and self-esteem. In: KR Fox (Ed.), The physical self: From motivation to well-being. Champaign, IL: Human Kinetics; 1997. P. 3-26.

22.Martin Ginis K, Bassett R. Exercise and Changes in Body Image, in Body Image. New York: The Guilford Press; 2011.

23.Williams PA, Cash TF. The effects of a circuit weight training program on the body images of college students. International Journal of Eating Disorders, 2001;30:75-82.

24.Campbell A, Hausenblas HA. Effects of exercise interventions on body image: A meta-analysis. Journal of Health Psychology, 2009;14:780-793. 


\section{Information about the authors:}

Pop Cristiana Lucretia; http://orcid.org/0000-0002-6445-8702; crispotir@yahoo.com; Physical Education and Sport Department, Bucharest University of Economic Studies; 140 Constantin Noica Street, sector 6, Bucharest, POB 060057, Romania.

Cite this article as: Pop Cristiana Lucretia. Body mass index and body image anxiety in a sample of undergraduate students. Physical education of students, 2018;22(2):77-82. doi:10.15561/20755279.2018.0204

The electronic version of this article is the complete one and can be found online at: http://www.sportedu.org.ua/index.php/PES/issue/archive

This is an Open Access article distributed under the terms of the Creative Commons Attribution License, which permits unrestricted use, distribution, and reproduction in any medium, provided the original work is properly cited (http://creativecommons.org/licenses/by/4.0/deed.en)

Received: 06.01.2018

Accepted: 30.01.2018; Published: 27.04.2018 